\title{
Cadeiras na Calçada: Plantão Comunitário no acolhimento e formação de redes
}

\author{
Chairs on the sidewalk: Community Duty as Welcoming \\ Practice and Networking
}

\author{
João Eduardo Coin de Carvalho ${ }^{1}$, Mariângela da Fonte Nogueira \\ Figueiredo ${ }^{2}$
}

1.Psicólogo, Doutor, Curso de Psicologia, Universidade Paulista, São Paulo-SP, Brasil.

2.Psicóloga, Secretaria de Estado da Saúde, São Paulo-SP, Brasil.

\begin{abstract}
Resumo
Introdução. O Plantão Comunitário (PC) é um grupo aberto mediado por plantonistas, cuja premissa é a aproximação para troca de experiências, sem hierarquias ou pressuposição de saberes. Objetivo. O objetivo do trabalho foi caracterizar a realização de Plantão Comunitário em uma favela de São Paulo, Brasil. Método. Foram registrados 64 encontros com 96 participantes. Os resultados foram submetidos a análise quantitativa e qualitativa. Resultados. as demandas foram classificadas nas seguintes categorías: saúde física e mental, questões familiares, falta de infraestructura básica, exposição à violência e ao tráfico de drogas, escola, desemprego e problemas financeiros. Conclusões. os resultados confirmam a função de cuidado exercida pelas mulheres da comunidade e as demandas e possibilidades de atuação profissional junto a crianças e adolescentes, e indicam a potencialidade do PC como prática de acolhida e para a construção de redes sociais.

Unitermos. psicología comunitária; psicologia; acolhimento; saúde comunitária; saúde pública
\end{abstract}

\begin{abstract}
Introduction. The Community Duty is an open group mediated by "plantonistas" whose premise is to make the participants to exchange experiences and build social nets. Objective. this work aimed to characterize the performance of Community Duty in a slum in São Paulo, Brazil. Method. Sixty four meetings with 96 participants were recorded. The results were submitted to a quantitative and qualitative analysis. Results. The demands were classified into categories: chemical dependency, poor physical and mental health, family issues, lack of basic infrastructure in the community, exposure to violence and drug dealing, complaints relating to school, unemployment, and financial problems. There were significant gender and age differences. Conclusions. the results indicated the potential of the Community Duty to welcoming, psychosocial orientation, and building a social network.

Keywords. community psychology; psychology; user embracement; community health; public health
\end{abstract}

Trabalho realizado na Universidade Paulista - UNIP, São Paulo-SP, Brasil.

Conflito de interesse: não

Recebido em: julho de 2017

Aceito em: $1 / 12 / 2017$

Endereço para correspondência: João EC Carvalho. Rua Japurá 55/617. São Paulo-SP, Brasil. CEP 01319-030. Email: joaocoin@yahoo.com 


\section{INTRODUÇÃO}

Na área de Saúde, uma intervenção em Psicologia Social Comunitária se dá junto a um grupo, comunidade ou instituição em condições de sofrimento que não permitem o reconhecimento e a instalação de projetos coletivos. Isso implica entender o sofrimento humano como um fenômeno ético-político, produzido pela vivência de desigualdades e injustiças sociais, não sendo uma característica do indivíduo, mas produto de um processo sócio histórico, político, econômico e cultural ${ }^{1,2}$, o que não se vê apenas na América Latina, mas em todo o mundo, exigindo um novo olhar e novas estratégias de enfrentamento ${ }^{3,4}$. Daí a importância de se compreender os saberes e a experiência cotidiana no âmbito dos grupos, em suas dimensões psicossocial e ético-política, articulando demandas com possibilidades de ações efetivas. A implantação de ações transformadoras nas comunidades mais pobres, apesar de poder ser compreendida como inerente à prática do psicólogo, ainda é um processo de conhecimento pautado por desafios metodológicos e políticos ${ }^{5,6}$. A hegemonia do modelo de atendimento individual na comunidade caracteriza intervenções que raramente consideram as condições de vida do grupo em que se realizam, alijando o grupo de uma participação ativa nessas mudanças. O psicólogo, ao priorizar esse tipo de atendimento, arrisca-se a atribuir à comunidade o rótulo de "desamparada", transformando os sujeitos em "beneficiários", podendo dar aos serviços uma conotação meramente assistencial ${ }^{7}$. Sob 
essa perspectiva, o grupo perde a oportunidade de construir suas próprias condições, saberes e autogestão, deixando de se colocar como agente ativo na solução de seus problemas ${ }^{8}$.

Desde 2003, são realizadas ações psicossociais na Vila Nova Tietê e na Cidade Nova, duas das cinco comunidades do Complexo da Funerária, na zona norte de São Paulo, com a participação de professores e alunos da graduação do curso de Psicologia da Universidade Paulista. Em 2006, na Vila Nova Tietê, teve início um serviço de atendimento à comunidade, constituído como grupo aberto e de participação espontânea, o Plantão Comunitário, cuja premissa é a aproximação dos participantes para a troca de experiências, sem hierarquias ou saberes pressupostos ${ }^{9}$. Os plantonistas atuam como facilitadores, procurando mediar os encontros de modo que os participantes interajam, discutindo entre si os problemas levantados. Os moradores são convidados a participar, mesmo que como ouvintes, pois a vivência de estar em um espaço de diálogo aberto pode propiciar o conhecimento, a partir da escuta atenta, ao perceber que outros compartilham problemas semelhantes ${ }^{10,11}$. Uma das ideias que fundamentam 0 Plantão Comunitário é que a transformação social não se dá a partir de mudanças individuais, mas, sim, coletivas, considerando o processo grupal como um conjunto que não pode ser reduzido à somatória de seus integrantes, desde que o próprio grupo é uma experiência histórica, construída 
em determinados espaço e tempo, nas relações cotidianas $^{12}$.

O dispositivo favorece, ainda, a ativação da rede social de contatos já existente entre vizinhos, familiares, amigos e conhecidos, estimulando a discussão de questões pertinentes à comunidade. Essa rede, um sistema aberto em permanente construção, construído individual e coletivamente $^{13}$ inclui também o plantonista, que é desafiado a abandonar a tendência a resolver questões individuais e emergenciais, reproduzindo práticas comuns no serviço público, para se engajar em projetos coletivos nos quais ele é consultor, mediador e parceiro.

Nestas circunstâncias, a prática do Plantão Comunitário tem ocorrido, estrategicamente, em conjunto com visitas domiciliares, entendidas como um trabalho de caráter educacional, assistencial e exploratório que atua na modalidade de cuidado, integrada à atenção psicossocial $^{14,15}$. As visitas são realizadas considerando os moradores que não podem ou não se dispõem a princípio a participar dos encontros, por não se sentirem à vontade em expor suas questões em um grupo. Um dos objetivos das visitas, assim, é prepará-los para que se sintam mais seguros para frequentar estes espaços públicos e comunitários.

Plantões e visitas estão associados a uma ação de acolhimento, o que significa entender as demandas sob a perspectiva da saúde pública no Brasil, como algo a ser observado em seu caráter social, como parte de um todo, 
uma proposta de ação que contribui para a emancipação e transformação dos sujeitos ${ }^{16,17}$. Nos encontros, as conversações, portanto, podem ser qualificadas como um "acolhimento dialogado", no sentido de fazer emergir sentidos comuns nos pontos de convergência das diversidades $^{18}$. No diálogo estabelecido entre plantonistas e participantes, todos têm a oportunidade de compartilhar vivências, reconhecendo e aceitando não só as suas próprias características e limitações, mas, também, tendo a oportunidade de reconhecer as demandas alheias, em uma troca de experiências que se constitui em fator de enriquecimento pessoal e da própria comunidade, à medida que se percebem problemas e possíveis soluções comuns a serem construídas a partir do conjunto dos saberes coletivos.

O objetivo do presente trabalho foi caracterizar e discutir a realização de Plantões Comunitários no Complexo da Funerária, na Zona Norte de São Paulo, identificando os participantes, as demandas, as ações desenroladas dentro do grupo, os benefícios e as dificuldades desta prática.

\section{MÉTODO}

\section{Amostra}

Participaram do estudo 96 moradores (63 mulheres) das comunidades Cidade Nova e Vila Nova Tietê (Complexo da Funerária) que estiveram nos encontros do Plantão Comunitário ou foram acessados através de visitas 
domiciliares, solicitadas pelos líderes comunitários ou por outros moradores. Não foram visitadas as casas de todos aqueles que participaram dos Plantões Comunitários.

O trabalho foi submetido ao Comitê de Ética em Pesquisa da Universidade Paulista (CAAE 0267.0.251.00010).

\section{Procedimento}

Os moradores foram acompanhados por quatro equipes de plantonistas-estagiários (11 alunos) do curso de Psicologia da Universidade Paulista, além do professorsupervisor. O Complexo da Funerária é um grupo de favelas situado na zona norte da cidade de São Paulo que abriga aproximadamente trinta e cinco mil pessoas. Os Plantões aconteceram na Vila Nova Tietê, com o apoio da União dos Moradores do bairro, em frente à Igreja Católica São José Operário, e na comunidade Cidade Nova, em frente à Igreja Batista, com o apoio dos líderes comunitários.

Como fonte primária de dados foram utilizados os relatórios de cada um dos encontros, produzidos pelos plantonistas durante 2010 e 2011, registros da interação dos plantonistas com a comunidade durante os encontros, das visitas domiciliares e da observação direta do entorno.

\section{Análise}

As informações quantitativas contidas nos relatórios foram organizadas, submetidas à análise estatística apropriada (Teste de qui quadrado) e os dados discursivos 
foram categorizadas pelos autores através de Análise de Conteúdo Temática ${ }^{19}$. A partir dos dados contidos nos relatos dos participantes objetivou-se apreender o sentido atribuído pelos membros da comunidade às questões por eles levantadas nos encontros, para, posteriormente, apreender o próprio processo de produção desses sentidos, no contexto da comunidade.

\section{RESULTADOS E DISCUSSÃO}

Os participantes $\mathrm{e}$ as demandas: diferenças por gênero e idade

No total, registraram-se 64 encontros nas duas comunidades. Na Cidade Nova foram 31 encontros, com sete visitas domiciliares, de 03/2010 a 06/2011. Na Vila Nova Tietê, de 10/2010 a 10/2011, foram 33 encontros, com oito visitas domiciliares. Estiveram nos plantões 96 participantes (65,6\% mulheres) de 5 a 77 anos, a maioria entre 20 e 59 anos (Tabela 1). As demandas apresentadas nas falas dos participantes (208) foram classificadas em nove categorias (Tabela 2): dependência química (14,4\%); problemas de saúde física e mental $(13,0 \%)$, questões familiares $(13 \%)$, falta de infraestrutura básica na comunidade $(12,5 \%)$, exposição à violência e ao tráfico de drogas $(11 \%)$; desemprego $(6,2 \%)$ e problemas financeiros $(6,3 \%)$, queixas relativas à escola $(8,2 \%)$. A dependência de álcool e drogas teve lugar destacado nas falas dos participantes $(\mathrm{N}=30)$. Verifica-se também uma grande concentração nas questões associadas à saúde (saúde física 
e mental; dependência química; queixa escolar), confirmando a saúde como tema central entre as preocupações dos moradores e a ausência de soluções satisfatórias, na compreensão destes participantes, nas políticas públicas, apesar do crescimento da atenção primária nos últimos anos no Brasil ${ }^{20}$.

Tabela 1. Descrição dos moradores participantes.

\begin{tabular}{|c|c|c|c|c|c|}
\hline & \multicolumn{2}{|c|}{ Cidade Nova } & \multicolumn{2}{|c|}{ Nova Tietê } & \multirow[b]{2}{*}{ Total } \\
\hline $\begin{array}{l}\text { Gênero } \\
\text { Idade }\end{array}$ & q & 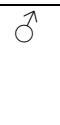 & q & $\hat{0}$ & \\
\hline$<20$ & 3 & 7 & 8 & 10 & 28 \\
\hline 20 a 39 & 10 & 2 & 9 & 8 & 29 \\
\hline 40 a 59 & 12 & 2 & 13 & 2 & 29 \\
\hline$>60$ & 1 & 0 & 7 & 2 & 10 \\
\hline Total & 26 & 11 & 37 & 22 & 96 \\
\hline
\end{tabular}

Tabela 2. Frequência das demandas por idade.

\begin{tabular}{|c|c|c|c|c|c|c|c|c|c|c|}
\hline Idade & $\begin{array}{l}\text { Infraestrutura } \\
\text { básica na } \\
\text { comunidade }\end{array}$ & $\begin{array}{l}\text { Saúde } \\
\text { física/mental }\end{array}$ & $\begin{array}{l}\text { Queixa } \\
\text { escolar/ } \\
\text { exclusão e } \\
\text { medicalização } \\
\text { de crianças }\end{array}$ & $\begin{array}{l}\text { Questões } \\
\text { familiares/ } \\
\text { conjugais }\end{array}$ & $\begin{array}{l}\text { Criminalidade } \\
\text { e violência }\end{array}$ & $\begin{array}{l}\text { Álcool } \\
\text { e } \\
\text { drogas }\end{array}$ & $\begin{array}{l}\text { Trabalho/ } \\
\text { desemprego }\end{array}$ & $\begin{array}{l}\text { Problemas } \\
\text { financieros }\end{array}$ & $\begin{array}{l}\text { Sem } \\
\text { demanda } \\
\text { específica }\end{array}$ & Total \\
\hline$<20$ & 3 & 4 & 3 & 5 & 6 & 9 & 5 & 1 & $28 *$ & 64 \\
\hline 20 a 39 & $9 *$ & 8 & 6 & 6 & 3 & 7 & 2 & 4 & 7 & 52 \\
\hline 40 a 59 & 6 & $10 *$ & $7 *$ & $11^{*}$ & 6 & 8 & 2 & 2 & 0 & 52 \\
\hline$>60$ & $8 *$ & 5 & 1 & 5 & $8 *$ & 6 & 4 & 2 & 1 & 40 \\
\hline Total & 26 & 27 & 17 & 27 & 23 & 30 & 13 & 9 & 36 & 208 \\
\hline
\end{tabular}

Constatou-se, ao longo dos encontros, que sistematicamente as demandas apresentadas estavam relacionadas a questões sociais (Tabelas 2 e 3). Assim também, nos relatos dos moradores muitos, direta ou indiretamente, afirmavam terem problemas ligados ao uso 
de álcool e drogas na família. Outras queixas comuns foram depressão e outros problemas de saúde física e mental; desestruturação familiar e desajustes conjugais; insatisfação no trabalho e problemas decorrentes da falta de uma atividade remunerada; mau atendimento pela rede pública de saúde; hiperatividade infantil, dificuldades de aprendizado e violência escolar. Os problemas de saúde física e mental relatados, muitas vezes, foram relacionados a atendimentos deficientes ou insatisfatórios da rede pública de saúde que atende aos moradores da comunidade, a qual é principal via de acesso para a obtenção de tratamento, medicamentos e informações sobre a prevenção e a manutenção de uma vida saudável. Isto sugere a ausência de uma das funções básicas da atenção primária, a acolhida, isto é, o apoio para a construção de uma ação profissional que busca o vínculo com a população ${ }^{17,21}$. Verificou-se, também, a desinformação em relação aos seus direitos enquanto cidadãos e em relação ao acesso a serviços públicos sociais, jurídicos e de saúde. É importante mencionar sua preocupação com relação ao futuro das crianças e jovens que estão crescendo no contexto da favela, em meio à violência, ao tráfico de drogas e à falta de perspectivas quanto ao futuro. 
Tabela 3. Frequência das demandas dos participantes por idade e gênero (total).

\begin{tabular}{|c|c|c|c|c|c|c|c|c|c|c|c|}
\hline & Idade & $\begin{array}{l}\text { Infraestrutura } \\
\text { básica na } \\
\text { comunidade }\end{array}$ & $\begin{array}{l}\text { Saúde } \\
\text { física/mental }\end{array}$ & $\begin{array}{l}\text { Queixa } \\
\text { escolar/ } \\
\text { exclusaõ e } \\
\text { medicalização } \\
\text { de crianças } \\
\end{array}$ & $\begin{array}{l}\text { Questões } \\
\text { familiares/ } \\
\text { Conjugais }\end{array}$ & $\begin{array}{l}\text { Criminalidade } \\
\text { e violência }\end{array}$ & $\begin{array}{l}\text { Alcool } \\
\text { e } \\
\text { drogas }\end{array}$ & $\begin{array}{l}\text { Trabalho/ } \\
\text { desemprego }\end{array}$ & $\begin{array}{l}\text { Problemas } \\
\text { financieros }\end{array}$ & $\begin{array}{l}\text { Sem } \\
\text { demanda } \\
\text { específica }\end{array}$ & Total \\
\hline \multirow{5}{*}{$\begin{array}{l}y \\
\frac{y}{0} \\
\frac{\bar{J}}{3} \\
\Sigma\end{array}$} & $<20$ & 3 & 0 & 2 & 2 & 2 & 4 & 1 & 0 & $13 *$ & 27 \\
\hline & 20 a 39 & 5 & $7 *$ & $6 *$ & 6 & 3 & 3 & 1 & 2 & 1 & 34 \\
\hline & 40 a 59 & 4 & 8* & $7 *$ & $9 *$ & 6 & 6 & 2 & 2 & 0 & 44 \\
\hline & $>60$ & 5 & 4 & 1 & 4 & $8^{*}$ & 5 & $4 *$ & 2 & 1 & 34 \\
\hline & Total & 17 & 19 & $16 *$ & 21 & 19 & 18 & 8 & 6 & $15 *$ & 139 \\
\hline
\end{tabular}

\begin{tabular}{|c|c|c|c|c|c|c|c|c|c|c|c|}
\hline \multirow{5}{*}{$\begin{array}{l}\text { 모 } \\
\text { d } \\
\text { 동 }\end{array}$} & $<20$ & 0 & 4 & 1 & 3 & 4* & 5 & 4* & 1 & $15 *$ & 37 \\
\hline & 20 a 39 & 4 & 1 & 0 & 0 & 0 & 4 & 1 & $2 *$ & 6 & 18 \\
\hline & 40 a 59 & 2 & 2 & 0 & $2 *$ & 0 & 2 & 0 & 0 & 0 & 8 \\
\hline & $>60$ & 3* & 1 & 0 & 1 & 0 & 1 & 0 & 0 & 0 & 6 \\
\hline & Total & 9 & 8 & 1 & 6 & 4 & 12 & 5 & 3 & $21 *$ & 69 \\
\hline
\end{tabular}

Tendo em vista a faixa etária dos participantes (Tabela 2), a ausência de demanda específica foi a mais prevalente das demandas entre as crianças e adolescentes $(p<0,0001)$, sugerindo que sua presença se presta mais para acompanhar as reuniões do que para propor questões que digam respeito a todos. De fato, uma marca dos Plantões foi a participação de crianças que vinham aos encontros para descobrir o que aqueles adultos de fora da comunidade faziam ali no meio da rua. Mais justo seria dizer que neste caso não havia a falta de uma demanda, mas um pedido mais franco por atenção e cuidado. Isto, que interrogava e desafiava os plantonistas, também era motivo de sensibilização e disparador do olhar para os jovens participantes, o que contraria os preconceitos comuns contra crianças e adolescentes, vistos como desinteressados, rebeldes e agressivos ${ }^{22}$. 
Nas outras faixas etárias, por outro lado, houve a presença constante de um tema trazido para o Plantão, indicando a importância das demandas como motor para a participação ${ }^{23}$ : na faixa de 20 a 39 anos, a questão da infraestrutura foi a mais prevalente $(p=0,04)$; na de 40 a 59 anos, as questões voltadas à saúde física e mental $(p=0,01)$, as questões relativas à escola $(p=0,02)$ e as familiares $(p=0,004)$ e na faixa acima de 60 anos, os temas da infraestrutura $(p=0,03)$, da criminalidade e violência $(p=0,01)$.

Quando comparados por gênero (Tabela 3), há diferenças importantes na presença e nas questões trazidas pelas mulheres e nas trazidas pelos homens, quanto à categoria "Queixa escolar" (mais frequente entre as mulheres; $\mathrm{p}<0,05$ ) e "Sem demanda específica" (mais frequente para os homens; $p<0,05)$. A maior frequência das mulheres nos Plantões mostra a disposição para o encontro e também a curiosidade sobre a presença dos plantonistas, o que pode ser compreendido na execução de sua ação de cuidado ${ }^{24}$, já que traziam demandas para a solução de problemas pessoais e familiares, não necessariamente para atendimento psicológico. Esta função de cuidado pode ser vista na identificação de diferentes temas, com uma maior prevalência de temas relacionados com a saúde e questões escolares no grupo de 20 a 39 anos $(p=0,05)$; os temas familiares $(p=0,03)$ e saúde $(p=0,05)$ no grupo 40 a 59 anos e o trabalho $(p=0,02)$ e a criminalidade $(p=0,009)$ no grupo com mais de 60 anos. 
Do lado dos homens, enquanto que os temas "femininos" (crianças e família) quase não apareceram nas suas falas, estes buscavam nos Plantões justamente tratar de temas como problemas financeiros $(p=0,04)$ no grupo de 20 a 39 anos; questões familiares $(p=0,05)$ no grupo de 40 a 50 anos; infraestrutura da comunidade $(p=0,002)$ no grupo com mais de 60 anos e no grupo de crianças e adolescentes os temas da criminalidade $(p=0,005)$ e trabalho $(p=0,003)$. A falta de um tema ("sem demanda específica") também se mostrou mais evidente entre os homens, especialmente se são refinados os resultados de crianças e adolescentes, o que sugere que as mulheres vinham ao Plantão para "resolver" questões, ou serem "cuidadas", o que não necessariamente aconteceu com os homens, mais avessos à ação de cuidado que o Plantão, mesmo que implicitamente, parecia oferecer. Isto concorda com a lógica do buscar cuidado como não sendo uma prática masculina ${ }^{25}$.

\section{A condição das mulheres e das crianças}

Segundo as falas dos participantes, a situação de exclusão social a que estão submetidos os moradores, traduzida na falta de ganhos, nas moradias precárias e na dificuldade em exercer plenamente a sua cidadania, propicia o recrudescimento de demandas de natureza pessoal, a falta de espaço para discutir os seus problemas e trazer suas questões, situação reforçada, no caso das mulheres, pela baixa autoestima e sua submissão ao 
gênero masculino. Tais fatores estão implicados na dependência econômica destas em relação aos seus parceiros e em conflitos de natureza relacional, como a violência na interação conjugal, bem como conflitos entre os membros da família, vinculados à geração de renda, como o desemprego e o subemprego. Especialmente entre as mulheres, as questões econômicas e culturais conduzem os sujeitos ao isolamento e ao sofrimento social ${ }^{3,4}$.

Em vários encontros, ficou implícita a dominação de gênero existente no contexto da comunidade: algumas moradoras optaram por conversar com uma plantonista mulher, assim como moradores preferiram conversar com um plantonista homem, como foi o caso de I: "minha esposa quis marcar psicólogo para mim, mas eu nunca quis ir", talvez se certificando, desse modo, que Psicologia também seria 'coisa de homem'.

Notou-se, ainda, que muitas moradoras não repartem preocupações com os parceiros, talvez com receio de reações mais exacerbadas da parte deles, como a operária $E$, que não conta os seus problemas profissionais ao marido, porque não quer deixá-lo "nervoso". Essas moradoras parecem ter herdado de suas mães e avós a tarefa de tomar para si o encargo de cuidar sozinhas das demandas emocionais de seus filhos e das suas próprias, talvez agradecidas por terem ao seu lado um mantenedor, num lugar em que a violência e o uso abusivo de álcool e drogas são características comuns a muitos dos homens, culpando-se por trazer-lhes transtornos, submissão que é 
outra faceta da violência e do sofrimento, e dos efeitos mais importantes da cultura patriarcal latino-americana ${ }^{26}$.

A naturalização da violência contra a mulher permeou o discurso de alguns moradores, como a aposentada F, que, ao comentar o estupro de uma menina de 14 anos, afirmou que "nessa idade, a moça não é mais tão criança para não saber onde está se metendo", culpabilizando, assim, a própria vítima pela violência que sofreu. Uma fala que atesta a subordinação da mulher aos projetos e desejos masculinos em uma condição que nega a alteridade, gera a dependência, a opressão e a violência ${ }^{27}$.

Sintomaticamente, considerando esta falta de espaço para a atenção e o cuidado, na maioria dos encontros, houve a companhia constante de crianças, que trataram os plantonistas como velhos conhecidos: conversaram, trouxeram demandas e questionamentos, pediram carinho. Isso se explicaria porque, ao sair do setting do consultório, a ação do psicólogo passa a ser facilitadora das diversas formas de protagonismo social ${ }^{10}$. Foi o caso da participação das crianças: elas se sentiram acolhidas, percebidas como interessantes e dignas de atenção.

Foi relevante o fato de as crianças perguntarem com frequência a respeito das relações entre os plantonistas, se eram casados ou namorados. Nos discursos das crianças que participaram, constatou-se também o quanto elas estavam interessadas na violência entre pares: "você e sua namorada brigam?", "você bate na sua mulher?". Muitas delas relataram presenciar e/ou serem vítimas de 
agressões físicas perpetradas por seus familiares. Importante frisar a importância de a criança poder e dever romper o silêncio que se instala em torno da violência doméstica, ela que exposta a esta condição também é vítima desta condição ${ }^{28}$. Isso contribui para romper com a ideia de que ninguém poderá protegê-la, já que, por conta da violência, percebe o papel dos adultos protetores como extremamente fragilizados - e sofre por saber. Este foi 0 caso de K (7 anos), que demonstrou consciência dos graves problemas sociais que afetam a sua família, tendo presenciado constantemente cenas de violência doméstica, provocadas pela dependência química de seus pais e de seu avô. A partir de uma consulta psiquiátrica na Unidade Básica de Saúde da região, passou a ser medicado devido às queixas relativas ao seu comportamento, por encaminhamento da diretoria da escola pública que ele frequenta. Ele foi diagnosticado como "hiperativo", sem que se considerassem as condições psicossociais em que ele está inserido, antes de estabelecer o diagnóstico.

Isso também se observou no caso de $L$ ( 8 anos), filho da manicure $\mathrm{N}$, que toma medicamentos para hiperatividade. Em visita domiciliar, constatou-se que o garoto, considerado "agitado", desde pequeno é obrigado pela mãe a passar o dia trancado em uma casa de dois cômodos, só saindo para ir à escola. Uma exclusão social similar ocorreu com G (8 anos), enteado da dona de casa W, o qual fora proibido pela diretora de frequentar a escola sem antes passar por um psiquiatra, encaminhando-o à 
Unidade Básica de Saúde, devido ao seu mau comportamento e "agitação" (sic). G vivia com os irmãos e a madrasta desde que sua mãe, dependente química, foi assassinada, fato do qual ele tinha conhecimento. O pai não participava de seu cotidiano.

Outras crianças, tidas como portadoras de algum distúrbio pelos próprios pais, foram levadas por eles ao Plantão, como a dona de casa $V$, que levou o filho L (5 anos), afirmando que ele teria dislexia, porque tinha dificuldade de aprendizagem e de concentração. Ela afirmou ter feito o "diagnóstico", com base no que ouviu falar a respeito da suposta doença do filho: "precisamos descobrir o que há de errado com ele, para ficar mais tranquilos".

Desta forma, familiares, médicos e educadores contribuíram para a reprodução de modelos segregativos e de marginalização daqueles que não se encaixam no padrão social exigido, reforçando os sistemas de produção da subjetividade dominante. Tal exclusão é pautada por discursos com base naquilo que estaria "faltando" em seus corpos, mentes, linguagem e comportamento ${ }^{29}$. As crianças da comunidade não se encaixam em um perfil idealizado de "alunos-padrão" por seus familiares e professores, os quais, por desinformação, omissão ou indiferença, podem acreditar ser mais "fácil" lidar com uma criança "medicada" - leia-se: apática - do que desenvolver estratégias pedagógicas - individuais e coletivas - para inseri-lo no 
contexto escolar, lidando com aquilo que a criança sabe e atua sobre sua condição social ${ }^{30}$.

Neste sentido, outra questão que contribui para que os moradores ponham na berlinda a instituição escolar é a violência que acontece dentro dos pátios e salas de aula. Um exemplo disso foi o diálogo entre a artesã $\mathrm{F}$ e a dona de casa $R$, que, com a mediação dos plantonistas, discutiram sobre o que poderia ser feito para reduzir a violência escolar. Elas concluíram que professores e inspetores devem prestar mais atenção aos alunos, que poderiam ser separados por idades, durante os intervalos, com atividades recreativas direcionadas, nos recreios, para evitar a formação de gangues e controlar jogos violentos, e os pais deveriam participar mais das atividades escolares dos filhos. Foi perguntado se conheciam pessoas com as mesmas queixas e sugeriu-se que se reunissem com a coordenação da escola, pois várias vozes se fazem ouvir melhor que uma. A artesã $F$ ficou surpresa em constatar que poderia haver soluções que não fossem baseadas apenas em vigiar e punir. Apesar de já ter contado com o apoio da comunidade, ela não pensara na possibilidade de reunir outros interessados a discutir a violência escolar com os representantes da instituição.

\section{Violência e dependência química}

Em um diálogo sobre o aumento da violência, a dona de casa $T$ comentou: "não vivíamos numa guerra. Fazia sacrifício, mas tinha paz. Guerra a gente enfrenta hoje, que 
não se tem sossego para nada. A gente não sabe o que vai ser dos nossos netos com tudo isso que está aí". A aposentada $A$ disse se sentir de mãos atadas quanto ao futuro de familiares já envolvidos com o crime. Ela relatou temer que o genro fugisse da penitenciária, onde cumpre pena por roubo, ao obter um indulto, afirmando que só Ihe restava "aconselhar". Desesperançados, alguns moradores, como a artesã $F$, não conseguem vislumbrar soluções para tentar coibir a criminalidade: "nem se o Exército entrasse aqui. Só um milagre de Deus". Esta opinião reforça a falta de fé nas ações de governo (políticas públicas) para satisfazer suas queixas, mas ao mesmo tempo indica uma preocupação com o futuro (os netos), que também é esperança de inclusão e marca uma nova etapa em suas vidas, com novas demandas ${ }^{31}$.

No discurso de algumas moradoras, percebeu-se, também, uma preocupação com o consumismo dos jovens, o qual, segundo elas, quando não efetivado pela falta de condições financeiras, poderia instigá-los a cometer crimes. Interessante notar que, no vocabulário de moradores, os jovens não roubam, "pegam", deixando implícita a ideia que, de algum modo, a apropriação ilícita de um bem de consumo inacessível se tornasse mais permissível. Antes de pensarem em entrar para a criminalidade, muitos jovens foram vilipendiados em seus direitos, vitimizados por uma violência estrutural, contra a qual não sabiam se defender. A má qualidade de vida e as possibilidades restritas de 
educação, lazer, saúde e trabalho, pode deixar os jovens ainda mais vulneráveis à interferência dos traficantes ${ }^{32}$.

Além da violência, outra questão presente na comunidade é a da dependência química. Muitos dos participantes dos encontros estavam direta ou indiretamente ligados às consequências do uso de álcool e das drogas, o qual parece ser um problema comum a muitas famílias da comunidade. Moradores relataram o rompimento de vínculos familiares em razão da dependência química de seus parentes. Outros denotaram o desgaste desses vínculos, decorrente das constantes recaídas de seus familiares com adição de álcool e drogas. Alie-se a esse estresse o acúmulo de responsabilidades afetivas e financeiras - a serem assumidas por conta de ter um dependente químico na família. Isso afeta especialmente as mães da comunidade, que, além de cuidar de seus próprios filhos, tentando prover tratamentos e zelar por sua segurança, também passam a ter de se responsabilizar por seus netos, em função da adicção dos pais.

Em alguns casos, familiares fomentaram a participação de dependentes químicos, no Plantão, como a dona de casa $L$, que procurou ajuda pela primeira vez para tratar o alcoolismo do marido, que bebe há 41 anos. $O$ ajudante geral $A$, filho da cabeleireira $L$, também participou do encontro várias vezes com o intuito de obter apoio em sua luta contra o uso de drogas, voluntariamente e por incentivo de sua mãe. Nesses e em outros casos similares, 
ressalta-se a importância da família no processo de tratamento, no sentido de fortalecer os laços sociais e os vínculos afetivos do dependente químico ${ }^{33}$.

\section{A realização dos plantões: tecendo a rede}

Para a realização dos Plantões Comunitários, eram colocadas cadeiras em semicírculo sobre a calçada, em frente às igrejas batista (Cidade Nova) e católica (Nova Tietê), ou da sede da União de Moradores de Vila Nova Tietê. Lá também eram afixados cartazes anunciando os propósitos do Plantão Comunitário: um espaço público aberto à comunidade, para conversar, contar problemas, compartilhar experiências, tirar dúvidas ou, simplesmente, escutar o que está sendo tratado. Aqueles que se dispusessem a participar eram convidados a estabelecer suas próprias pautas, ritmos e compromissos, em encontros em que todos são protagonistas. Por conta do mau tempo ou da falta de condições adequadas para a instalação na calçada, como durante a realização de obras de pavimentação na comunidade, algumas vezes o Plantão ocorreu dentro dos salões da igreja batista, na Cidade Nova, e da igreja católica São José Operário, na Vila Nova Tietê, além de utilizar ali, também, o salão da União dos Moradores. Os grupos seguiram procederes prédeterminados, restritos semanalmente a um único dia e horário.

Com o objetivo de divulgar o Plantão Comunitário, os estagiários distribuíam panfletos anunciando data, horários 
e locais onde ocorreriam os encontros. Para isso, também foi solicitada permissão aos comerciantes da comunidade para que se deixasse os panfletos à disposição dos moradores, além de se contar com o apoio das agentes comunitárias do Serviço de Assistência Social à Família (SASF) Vila Maria-Vila Guilherme, que ajudaram na distribuição. Desse modo, a divulgação do Plantão tornouse mais abrangente sem ser impositiva. Foram afixados, ainda, cartazes com o mesmo teor dos panfletos nos murais das igrejas da vizinhança e no salão de cabeleireira de uma das líderes da comunidade.

$\mathrm{Na}$ relação como os moradores, eles, sociáveis e acolhedores, demonstraram sempre curiosidade em saber por que os plantonistas estavam ali. Conversavam com estes de maneira informal, como se os plantonistas fossem pessoas próximas. De fato, quando surgiram na comunidade, dispondo as cadeiras na calçada, tornaram-se próximos a eles, pois, de certa forma, foi como se estivessem sentados em seus quintais, como se colocassem cadeiras em frente aos seus portões.

A comunidade é pública, as ruas que sediam o Plantão são públicas. Mas, especialmente na Vila Nova Tietê, a Rua São Felipe - sede dos Plantões - não é uma simples via: lá, décadas atrás, um aglomerado de barracos começou a se estruturar enquanto comunidade. Os líderes locais instalaram suas famílias e construíram suas casas e suas histórias na São Felipe, e, até hoje, trabalham ou moram nela. Essa rua representa uma possibilidade de destino, não 
só no sentido literal: estão lá os que venceram juntos inúmeras batalhas cotidianas contra a miséria, lutando ao lado de parentes e vizinhos. O Plantão estabeleceu-se, então, na espinha dorsal da Nova Tietê, onde a ligação entre um sonho compartilhado e a atitude coletiva foram e são decisivos nas transformações sociais da comunidade.

A situação na Cidade Nova não foi muito diferente. Os Plantões aconteceram na principal rua do território, onde também estão, ao longo de cerca de 300 metros, além da igreja e do comércio local, duas escolas municipais (ensino infantil e fundamental), uma creche e um equipamento de assistência social que atende crianças e adolescentes no contraturno. A melhor escolha para os Plantões, ideal para que lançássemos a nossa "rede", a rua era como a entrada para o labirinto da comunidade, possibilidade de se encontrar e de se perder em meio às ruelas, praças e becos que a compõem.

Apesar da receptividade ao Plantão, um morador falou abertamente sobre o desconforto que a presença de psicólogos e estudantes causaria a alguns membros da comunidade. Na Vila Nova Tietê, por outro lado, um comerciante e líder comunitário afirmou apreciar a atuação do Plantão, ao contrário de outros moradores, que "não gostam da presença de gente de fora". Essa atitude pode constituir um "mecanismo de defesa coletivo", na tentativa de estabelecer controle social sobre quem transita pelo contexto comunitário ${ }^{12}$. Assim, aqueles considerados como não pertencentes ao espaço, ao ingressarem na favela, 
tendem a ser percebidos como corpos estranhos e potencialmente ameaçadores ${ }^{8,34}$.

Um dos objetivos do Plantão consistiu em facilitar as discussões de modo que o grupo assumisse o lugar de protagonista, abrindo-se para novas possibilidades de viver a cidadania. Um exemplo disso foi a discussão levantada pela cabeleireira $L$ e pela dona de casa $N$, que queriam saber se não promoveríamos eventos, "como as outras psicólogas... Precisa agitar um pouco isso aqui". Disseram que não daria certo se o encontro fosse feito por elas. Os plantonistas assinalaram que era necessário que tentassem, antes de vaticinar o seu insucesso. Foi por meio desse tipo de intervenção, sem paternalismo, que se almejou contribuir para o empoderamento dos moradores, para que percebam ter condições de mudar as suas realidades. No Plantão, é preciso deixar de lado a postura de saber o que é melhor para a vida do outro, refletindo sobre novas formas de sentir, agir e pensar sobre si mesmo, num contínuo processo de construção e reconstrução da subjetividade de todos os envolvidos ${ }^{9}$.

Observou-se que o dispositivo incentivou a solidariedade entre moradores. Em vários encontros, muitos se dispuseram a ajudar vizinhos, como foi o caso da artesã $F$, que se propôs a ensinar artesanato para a dona de casa $R$ e no abrigo de dependentes químicos da pedagoga L M, assim como esta se ofereceu para ajudar um parente de $F$, usuário de crack. A dona de casa $R$, por sua vez, ofereceu-se para ajudar a artesã $F$, quando esta 
esteve adoentada. $\mathrm{E}$ os líderes comunitários, como $\mathrm{Z}$, a dona-de-casa $\mathrm{N}$ e a cabeleireira $\mathrm{L}$, que recomendaram a inúmeros moradores que fossem ao Plantão, sugerindo, ainda, a realização de visitas domiciliares, acompanhando os plantonistas às residências. Alguns moradores da Cidade Nova e da Nova Tietê, inclusive, voluntariamente ajudaram a divulgar os encontros, distribuindo panfletos informativos.

Com eles, os plantonistas começaram a aprender a tecer: um fio aqui, um ponto acolá, que se liga com outro. Para isso, é preciso ter disposição para rever os próprios preconceitos e ideias cristalizadas, a ressignificar sentimentos, a cada encontro. Plantonistas e moradores começaram juntos a construir uma rede, acessível a quem quiser, disponível a todos. Uma rede de corpos, ideias e vontades.

\section{CONCLUSÃO}

Ações como o Plantão Comunitário, que visam promover a autonomia de grupos em situação de exclusão, sem implicar custos ou o preparo de grandes espaços, usando apenas "cadeiras na calçada", são adequadas para - levantamento e o encaminhamento de demandas psicossociais junto às comunidades em condições de exclusão. Para conhecer e ser conhecido. A vivência cotidiana e a participação em atividades psicossociais que possibilitam o encontro criam e renovam os símbolos de identidade dos moradores, e também dos plantonistas, que 
estabelecem e reconhecem um campo de atuação profissional fora do setting clínico. Esse dispositivo de empoderamento pode propiciar a construção de estratégias de resistência às situações de exclusão social, ajudando a tecer laços entre os moradores, à medida que estes passam a ressignificar as suas próprias questões, compartilhando experiências. Os resultados indicaram a potencialidade do dispositivo para o acolhimento, a orientação psicossocial e para viabilizar a construção de uma rede social voltada à saúde da comunidade.

\section{AGRADECIMENTOS}

Os autores agradecem o apoio recebido da ViceReitoria de Pós-Graduação e Pesquisa da UNIPUniversidade Paulista.

\section{REFERÊNCIAS}

1.Sawaia BB. O sofrimento ético-político como categoria de análise da dialética exclusão/inclusão. In: Sawaia BB, organizadora. As artimanhas da exclusão: análise psicossocial e ética da desigualdade social. Petrópolis: Vozes; 1999, p.97-118.

2.Carvalho JEC. Violência e sofrimento social: a resistência feminina na obra de Veena Das. Saúde e Sociedade 2008;17:9-18. https://doi.org/10.1590/S0104-12902008000300003

3.Das V. Critical events: An anthropological perspective on contemporary India. New Delhi: Oxford University Press; 1996, 240p. 4.Kleinman A, Das V, Lock M (Orgs.). Social suffering. Berkeley: University of California Press; 1997, 434p.

5.Campbell C. Community mobilisation in the 21st century: Updating our theory of social change? J Health Psychol 2014;19:46-59. https://doi.org/10.1177/1359105313500262

6.Saforcada ET. Salud comunitaria, gestión de salud positiva y determinantes sociales de la salud y la enfermedad. Aletheia 2012;37:7-22.

em: http://pepsic.bvsalud.org/pdf/aletheia/n37/n37a02.pdf 
7.Mendonça VLM. Produção de subjetividade e exercício de cidadania: efeitos da prática em psicologia comunitária. Pesquisas e Práticas Psicossociais 2007;2:34-43. Disponível em: http:// www.ufsj.edu.br/portal-repositorio/File/revistalapip/5artigoword.doc 8. Montero M. El fortalecimiento en la comunidad, sus dificultades y alcances. Universitas Psychologica 2009;8:615-26. Disponível em: http://revistas.javeriana.edu.co/index.php/revPsycho/article/view/61 $\underline{1}$

9.Carvalho JEC, Ostronoff VH. Cuidado e transformação social: avaliação da implantação do Turno comunitário no Complexo da Funerária. Estud Psicol 2014;19:89-156. https://doi.org/10.1590/S1413-294X2014000200006

10.Ramos C, Carvalho JEC. Espaço e subjetividade: formação e intervenção em psicologia comunitária. Psicologia e Sociedade 2008;20:174-80. https://doi.org/10.1590/S0102-

71822008000200004

11.Ostronoff $\mathrm{VH}$, Fávero $\mathrm{CB}$, Baldin PD. Uma experiência de supervisão em oficinas de criatividade. In: Cupertino CMB, organizadora. Espaços de criação em psicologia: oficinas na prática São Paulo: Annablume; 2008, p.77-94.

12. Martins STF. Processo grupal e a questão do poder em MartinBaró. Psicologia e Sociedade 2003;15:202-3. https://doi.org/10.1590/S0102-71822003000100011

13. Meneses MPR, Sarriera JC. Redes sociais na investigação psicossocial. Aletheia 2005;21:53-67. Disponível em:

http://pepsic.bvsalud.org/scielo.php?pid=S1413-

03942005000100006 \&script $=$ sci arttext

14.Tandon SD, Mercer CD, Saylor EL, Duggan A. Paraprofessional home visitors' perspectives on addressing poor mental health, substance abuse, and domestic violence: A qualitative study. Early Childhood Res Quarterl 2008;23:419-28. https://doi.org/10.1016/j.ecresq.2008.02.002

15.Teixeira CP. Visita domiciliar: um instrumento de intervenção. Sociedade em Debate 2009;15:165-78. Disponível em: http://revistas.ucpel.tche.br/index.php/rsd/article/view/365

16.Fracolli LA, Zoboli ELCP. Descrição e análise do acolhimento: uma contribuição para o Programa de Saúde da Família. Rev Escola Enferm 2004;38:143-51. https://doi.org/10.1590/S0080-

62342004000200004

17.Santos IMV, Santos AM. Acolhimento no Programa Saúde da Família: revisão das abordagens em periódicos brasileiros. Rev Salud Pública 2011;13:703-16. $\quad$ https://doi.org/10.1590/S012400642011000400015

18. Teixeira RR. O acolhimento num serviço de saúde entendido como uma rede de conversações. In: Pinheiro R, Mattos RA (org.) Construção da integralidade: cotidiano, saberes e práticas de saúde. Rio de Janeiro: UERJ/MS/ABRASCO; 2003, p.89-111.

19.Bardin L. Análise de conteúdo. Rio de Janeiro: Edições 70 - Brasil; 1986, 280p. 
20.Malta DC, Santos MAS, Stopa SR, Vieira JEB, Melo EA, Dos Reis AAC. A cobertura da estratégia de Saúde da Família (eSF) no Brasil, segundo a Pesquisa Nacional de Saúde, 2013. Ciência Saúde Col 2016;21:327-38. https://doi.org/10.1590/1413-

$\underline{81232015212.23602015}$

21.Campos GWS. Reforma política e sanitária: a sustentabilidade do SUS em questão. Ciência Saúde Col 2007;12:301-6. https://doi.org/10.1590/S1413-81232007000200002

22.Burman E. Deconstructing developmental psychology. Londres: Routledge; 2008, 368p.

23. Montero M. Introducción a la psicología comunitaria: desarrollo, conceptos y procesos. Buenos Aires: Paidós; 2011, 320p.

24.Schraiber LB, D'oliveira AFPL. La perspectiva de género y los profesionales de la salud: apuntes desde la salud colectiva brasileña. Salud Col 2014;10:301-12. Disponível em: http://www.scielo.org.ar/scielo.php?script=sci arttext\&pid=S1851$82652014000300002 \& \operatorname{lng}=e s \& n r m=$ iso

25.Gomes R, Nascimento EF, Araújo FC. Por que os homens buscam menos os serviços de saúde do que as mulheres? As explicações de homens com baixa escolaridade e homens com ensino superior. Cad Saúde Púb 2007;23:565-74. https://doi.org/10.1590/S0102$311 \times 2007000300015$

26.Narvaz MG, Koller SH. Mulheres vítimas de violência doméstica: Compreendendo subjetividades assujeitadas. Psico 2006;37:7-13. Disponível

em:

http://revistaseletronicas.pucrs.br/ojs/index.php/revistapsico/article/ viewFile/1405/1105

27. Narvaz MG, Koller SH. Famílias e patriarcado: da prescrição normativa à subversão criativa. Psicol Soc 2006;18:49-55. https://doi.org/10.1590/S0102-71822006000100007

28. Holden GW. Children exposed to domestic violence and child abuse: Terminology and taxonomy. Clin Child Famil Psychol Rev 2003;6:151-60. https://doi.org/10.1023/A:1024906315255

29.Caliman LV. A constituição sócio-médica do "fato TDAH". Psicol Soc 2009; 21:135-44. Disponível em: http://www.scielo.br/pdf/psoc/v21n1/16.pdf

30. Meira MEM. Para uma crítica da medicalização na educação. Rev Assoc Bras Psicol Esc Edu 2012;16:135-42. https://doi.org/10.1590/S1413-85572012000100014

31.Carvalho JEC, Esposito FCF. Desafios nas ações de atenção primária: estudo sobre a instalação de programa de visitas domiciliares para mães adolescentes. Aletheia 2012;37:149-61. Disponível

em:

http://www.redalyc.org/articulo.oa?id $=115026222009$

32. Fonseca FF, Sena RKR, Santos RLA, Dias OV, Costa SM. As vulnerabilidades na infância e adolescência e as políticas públicas brasileiras de intervenção. Rev Paul Ped 2013;31:258-64. https://doi.org/10.1590/S0103-05822013000200019 
33.Schenker M, Minayo MCS. A importância da família no tratamento do uso abusivo de drogas: uma revisão da literatura. Cad Saúde Púb 2004;20:649-59.

https://doi.org/10.1590/S0102311X2004000300002

34.Tavares SMG, Albertini P. Moradia e corporeidade em espaços liminares: um estudo sobre formas de subjetividade na favela. Paidéia $\quad 2005 ; 15: 299-308 . \quad$ https://doi.org/10.1590/S0103$\underline{863 \times 2005000200017}$ 